CUADERNOS DE ESTUDIOS GALLEGOS, LVIII N. ${ }^{\circ} 124$, enero-diciembre (2011), pp. 183-196

ISSN 0210-847 X

\title{
EL ARTE DEL BORDADO EN SANTIAGO DE COMPOSTELA. NUEVOS DATOS SOBRE BORDADORES DE LOS SIGLOS XVI Y XVII
}

Jesús Aguilar DíAZ

Universidad de Sevilla 


\title{
EL ARTE DEL BORDADO EN SANTIAGO DE COMPOSTELA. NUEVOS DATOS SOBRE BORDADORES DE LOS SIGLOS XVI Y XVII
}

\section{RESUMEN}

En este artículo se aportan nuevos datos de bordadores compostelanos de los siglos XVI y XVII. Se incluyen noticias relacionadas con la vida de estos artífices y con la producción artística de los mismos, es decir, contratos, conciertos, etc. Es el resultado de un minucioso trabajo de investigación en el archivo de la Catedral de Santiago de Compostela y en el Histórico Universitario de la misma ciudad. Con ello pretendemos profundizar en esta parcela de la historia del arte gallega por muchos olvidada y marcar un punto de partida a futuras investigaciones.

PALABRAS ClAVE: Bordados, bordadores, ornamentos litúrgicos, Santiago de Compostela, siglos XVI y XVII.

\section{THE ART OF THE EMBROIDERY IN SANTIAGO DE COMPOSTELA. NEW INFORMATION ON EMBROIDERERS OF THE $16^{\mathrm{TH}}$ AND $17^{\mathrm{TH}}$ CENTURIES}

\begin{abstract}
In this article there is contributed new information from Santiago de Compostela embroiderers of the 16th and 17th century. There includes news related to the life of these makers and to the artistic production of the same ones, that is to say, contracts, concerts, etc. It is the result of a meticulous work of investigation in the file of the Cathedral of Santiago de Compostela and in the Historical University of the same city. With it we try to penetrate into this plot of the Galician history of the art for many forgotten and to mark a point of item to future investigations.
\end{abstract}

KEY WORDS: Embroideries, embroiderer, liturgical ornaments, Santiago de Compostela, $16^{\text {th }}$ and $17^{\text {th }}$ Centuries. 
Recibido/Received: 30/09/2010

Aceptado/Accepted: 27/07/2011

$\mathrm{E}$ L arte del bordado es uno de los grandes desconocidos dentro de la historiografía específica. Hasta hace poco no conocíamos estudios realizados con estricta metodología universitaria que se encargaran de analizar e investigar dicha parcela de las artes ornamentales o suntuarias.

Este tipo de manifestaciones han sido incluidas habitualmente en las mal llamadas artes menores. Concepción peyorativa de la que ha conseguido excluirse, por ejemplo, el campo de la platería gracias a un buen número de trabajos de riguroso carácter científico en torno a esta materia. Ni que decir tiene que el arte del bordado sobresale no solamente por la repercusión que tuvo en ciertos momentos de la historia sino también por la calidad técnica y plástica de sus composiciones.

Fue tenido por algunos en tal aprecio que por ejemplo el conde de Laborde en su Glossaire français du moyen âge, refiriéndose a los bordados anteriores al siglo XVI, afirma que "el mayor servicio que podría hacerse para escribir la historia de las Artes, sería el escribir la del bordado; por cuanto, no es el complemento, sino la introducción y el acompañante obligado de la verdadera historia de la Pintura" 1 . Hay que precisar que nos encontramos con valiosas piezas de singular importancia. Entre ellas se incluyen un extenso corpus tipológico como capas, casullas, dalmáticas, mitras, palios, mangas de cruces, frontales de altar, cubrecálices, etc. A pesar de todo lo expuesto anteriormente, no nos podemos olvidar de algunas monografías donde de manera brillante se ha ocupado, en los últimos años, de esta parcela artística. Citeremos las obras de Carmen Eisman Lasaga, Manuel Pérez Sánchez o Ana María Agreda Pino².

\footnotetext{
${ }^{1}$ DE FARCY, Louis: La broderie du XIe siecle jusqu'a nos jours d'apres des specimens authentiques et les anciens inventaires. Angers, 1890, p, 3.

2 AGREDA PINO, Ana María: Los ornamentos en las iglesias zaragozanas. Siglos XVI-XVIII. Institución "Fernando el Católico". Excm. Diputación de Zaragoza, 2001. PÉREZ SÁNCHEZ, Manuel: El arte del bordado y del tejido en Murcia. Siglos XVI-XX. Universidad de Murcia, 1999. EISMAN LASAGA, Carmen: El arte del bordado en Granada. Granada, 1988.
} 
El caso del bordado gallego, en general, y el de Santiago de Compostela, en particular no es una excepción. Como ya apuntábamos en otra publicación ${ }^{3}$, son muy pocos los trabajos que conocemos donde se aborda el tema. Nada se ha escrito sobre si existió, por ejemplo, un gremio de bordadores en la ciudad compostelana. Los artistas se solían agrupar en cofradías. En la de Santa Apolonia, fundada en la iglesia del mismo nombre en 1669 , se reunían los cordoneros y calceteros ${ }^{4}$. Si tenemos, en cambio, más noticias sobre otras instituciones gremiales como la de los sastres o alfayates. Este oficio debió de gozar de cierta importancia en la capital gallega debido a que estaba asociado estrechamente a otros más artísticos como el de Bordadores o Brosladores para la realización, fundamentalmente, de ornamentos sagrados ${ }^{5}$. No obstante, hemos hallado un documento donde se cita al bordador Juan de Romay como mayordomo de la cofradía de San Esteban. Por tanto, es posible que este conjunto de artífices se reunieran en torno a dicha institución ${ }^{6}$.

En cuanto a los artistas del siglo XVI que trabajan en la ciudad compostelana conocemos más datos ${ }^{7}$. Hacía 1510 hay que situar a Juan de Medina bordador en Santiago. También hay que citar a Fernando Álvarez Rebellón, que en el primer tercio del Quinientos realiza su labor ${ }^{8}$. De Fernán Díaz, del que hasta ahora nada sabíamos con anterioridad a 1541, tenemos constancia de algunos trabajos realizados para la ciudad de Pontevedra y para la Catedral compostelana ${ }^{9}$. Otro bordador de la primera mitad del siglo XVI, avecindado en Santiago, fue Pedro Fernández. Pero, sin duda, el más importante de los brosladores de esta ciudad gallega por entonces fue Gonzalo de Luaces. Sobre dicho autor poseemos numerosos datos de su vida y obra. Además de la ejecución de un gran número de ornamentos para poblaciones como Noya, Ordenes, Banga, llevó a cabo otras tantas para la catedral de Santiago de Compostela ${ }^{10}$. De la primera mitad del siglo es Fernando Vázquez de quien hemos obtenido algunos datos biográficos como su

\footnotetext{
3 AGUILAR DÍAZ, Jesús: "Iconografía mariana en los ornamentos litúrgicos de la catedral de Santiago de Compostela", en Actas del Congreso Internacional Mariano: María signo de identidad de los pueblos cristianos". Gibraltar, 2010 (en prensa).

${ }^{4}$ RODRÍGUEZ GONZÁLEZ, ÁNGEL: “Cofradías y gremios de Santiago”, en Compostelanum. Sección de estudios Jacobeos. V, XXXI. Números 3 y 4. Santiago de Compostela, 1985. Julio-Diciembre, p. 467.

5 BOUZA BREY, Fermín: "La Cofradía Gremial de Sastres de Santiago de Compostela", en Compostellanum,. Sección de estudios Jacobeos. V. VII, nº 4. Santiago de Compostela, 1962. OctubreDiciembre, p. 571.

${ }^{6}$ Archivo Catedral de Santiago de Compostela (en adelante ACS). P101, fol. 129v. 15-02-1588.

7 AGUILAR DÍAZ, Jesús: "Iconografía mariana en los ornamentos litúrgicos de la catedral de Santiago de Compostela". Op. cit. (en prensa).

8 PÉREZ CONSTANTI, Pablo: Diccionario de artistas que florecieron en Galicia durante los siglos XVI y XVII. Edición facsímil. Santiago de Compostela, 1988, pp. 13-14.

${ }^{9}$ Ibidem., pp. 151-153.

${ }^{10}$ Ibid., pp 348-3551.
} 
testamento otorgado el 13 de abril de $1557^{11}$. Y en los últimos años del Quinientos, pero de mayor envergadura artística, es el anteriormente citado Juan de Romay. Conocemos que en 1586 realizó unas andas de terciopelo carmesí, bordadas en oro de Milán para la capilla de Nuestra Señora de la Corticela de la Catedral de Santiago de Compostela ${ }^{12}$.

Del Seiscientos también existen referencias de una amplia nómina de bordadores que viven y trabajan en la ciudad compostelana. A mediados del siglo se encuentra Juan Fernández quien en 1661 hizo para la catedral algunos ornamen$\operatorname{tos}^{13}$. Llamativa es la presencia de Diego Grande, bordador de origen flamenco, del que solo se sabe que en 1686 cobró mil doscientos cuarenta reales por aderezar los tapices de la sala capitular y un terno colorado de la catedral ${ }^{14}$. En los primeros años del siglo XVII trabaja Alonso de Castro. Tenemos constancia de la realización de algunos ornamentos litúrgicos para la parroquial de San Vicente de Camouco en Puentedeume, para la iglesia de San Vicente de Berres en Estrada y la cofradía de Santa Margarita, en San Mamed de Loño ${ }^{15}$. En 1635 Benito de Mata pide al Concejo se le expidiese título o carta de examen. Nombrado examinador Miguel Suárez de Romay, este declaró hallarle "abil y suficiente en lo tocante al bordar para azer oro matizado y peleteados, formaciones de todas suertes...". Anteriores a esta fecha se pueden fijar la realización de algunas obras como la llevada a cabo para Santa María de Alón en Negreira. Otras obras importantes son el pendón para la cofradía del Rosario de Santa Marina de Cambados; varios ornamentos litúrgicos para la capilla del Gran Hospital Real de Santiago y otras tantas prendas para la catedral de Santiago entre los años 1649 y $1658^{16}$. El hijo de este último, Benito Antonio de Mata también se dedicó al oficio paterno. Nacido en 1641 solo conocíamos algunas intervenciones para la Catedral de Santiago ${ }^{17}$. Avecindado en la parroquia de San Benito de la ciudad compostelana estuvo el bordador Álvaro Rivadeneyra quien estuvo al servicio de la catedral realizando varias obras para ella como tres mitras y la terminación bordada de una capa negra del terno rico de difuntos entre los años 1632 y $1634^{18}$. Discípulo de Juan de Romay fue Miguel Suárez de Romay, natural de la villa de Padrón y vecino de la ciudad de Santiago. En la documentación figura ya como maestro bordador en contratos de obras de su oficio en 1610 para llevar a cabo

\footnotetext{
11 Ibid., p. 545.

12 Ibid., pp- 487-488.

13 PÉREZ CONSTANTI, Pablo: Diccionario de artistas que florecieron en Galicia durante los siglos XVI y XVII. Op. cit., p. 186.

14 Ibid., p. 272.

15 Ibid., p. 279.

16 Ibid., pp. 372-374.

17 Ibid., pp. 374-375.

18 Ibid., p. 465.
} 
una casulla para San Vicente de Vilouchada en Ordenes y un terno de damasco para Santa María de Papucín en la misma localidad. La última noticia que tenemos de él es su presencia como examinador de Benito de Mata en $1635^{19}$.

Algunas publicaciones afirman que en el siglo XVIII no existieron bordadores gallegos, limitándose a nombrar la fábrica toledana de Miguel Molero como proveedora de ornamentos litúrgicos ${ }^{20}$. Nosotros hemos constatado la actividad de, aunque pocos, algunos bordadores compostelanos. En 16 de marzo de 1722 está fechada una carta de pago en la que se especifica el pago de doscientos y nueve reales con veinticuatro maravedíes al bordador Domingo Liñán por la realización de ocho florones para el terno nuevo rico de la Santa Catedral ${ }^{21}$. En 1723 se la pagan cuatrocientos reales al mismo artista por la bordadura de unos reposteros ${ }^{22}$. Otro artífice aparece en los libros de fábrica. Antonio Tonzeda recibe por parte del fabriquero cuatrocientos reales por bordar unos florones de oro para el terno y paños de púlpito en $1731^{23}$. El mismo broslador borda ocho florones para el terno morado en 1645 , por lo que recibe doscientos y veinticuatro reales ${ }^{24}$. Por otra parte el cabildo paga al bordador Manuel Díaz sesenta reales por componer la mitra con que se regaló al Ilustrísimo Sr. Arzobispo Rajoy. La carta de pago está fechada el 2 de agosto de $1751^{25}$. Tres años más tarde se le cita de nuevo por la restauración del paño de cáliz blanco que había donado el señor Monrroi ${ }^{26}$.

Como hemos visto el arte del bordado era un quehacer prácticamente exclusivo para hombres. Sin embargo también hemos constatado la presencia de alguna mujer. Normalmente al fallecer sus maridos, estas asumían directamente el control del taller y se encargaban de realizar los trabajos que demandaban los clientes ${ }^{27}$. A la muerte de Gonzalo de Luaces, su esposa, Isabel Vázquez, también bordadora, continúo algún tiempo al frente del importante obrador para concluir algunas obras que su marido dejó comenzadas ${ }^{28}$. Al igual que ocurría en el siglo anterior con Luaces, al morir Juan de Romay, su mujer Catalina de Palomares sigue trabajando en el taller familiar ${ }^{29}$.

\footnotetext{
19 Ibid., pp. 523-524.

${ }^{20}$ COUSELO BOUZAS, J: Galicia artística en el siglo XVIII y primer tercio del XIX. Salamanca, 2005, p. 168.

21 ACS. Fábrica, Libro 4 ${ }^{\circ}$ 1716-1756, fol. 45 r.

22 ACS. Fábrica, Libro 4 . 1716-1756, fol. 74 r.

23 ACS. Fábrica, Libro 4º 1716-1756, fol. 131r.

24 ACS. Fábrica, Libro 4º 1716-1756, fol. 332 vº.

25 ACS. Fábrica, Libro $4^{\circ}$. 1716-1756, fol. 444 r.

26 ACS. Fábrica, Libro 4º 1716-1756, fol. 506 r.

27 Sobre este particular consultar: AGREDA PINO, Ana María: "El trabajo de la mujer en los obradores de bordado zaragozanos", en Artigrama. Número 14. Zaragoza, 2000, pp. 293-312.

28 PÉREZ CONSTANTI, Pablo: Diccionario de artistas que florecieron en Galicia durante los siglos XVI y XVII. Op. cit., p. 546.

29 Ibid., p. 416.
} 
Tras estas consideraciones generales nos disponemos a analizar una serie de nuevas noticias acerca de bordadores compostelanos del siglo XVI y XVII. Algunos de los cuales ya han sido citados anteriormente y otros se nombran por primera vez. Toda la información se ha extraída del Archivo de la Catedral de Santiago de Compostela y del Archivo Histórico Universitario de la misma ciudad. Los enumeraremos por orden cronológico.

FRANCISCO DE BURGOS

En 1536 Bonifacio de Almonacir, cardenal mayor en Santiago y vicario del Dean en nombre propio y el de otros beneficiados de la Iglesia de Santiago firma una obligación a favor de Francisco de Burgos, vecino de Medina de Rioseco, de pagarle ciento veinticuatro ducados de oro que le debía ${ }^{30}$.

\section{PEDRO FERNÁNDEZ}

Juan López de Camba, racionero de Santiago, arrienda por diez años a Pedro Fernández, bordador de Santiago, una casa en la Cruz do Vilar por nueve ducados de renta anual ${ }^{31}$.

\section{FERNÁNDEZ DE GANZA}

Hemos encontrado el documento donde Fernán López de Gayoso, en nombre de Juan de Gayoso, arrienda por un año al bordador Fernández de Ganza, vecino de Santiago, el beneficio mitad sin cura de San Breixo de Sergude con sus frutos y rentas por siete mil quinientos maravedíes de renta ${ }^{32}$.

\section{FERNÁN DÍAZ}

Se cita por primera vez en 1539. Concretamente en un contrato por el que Elvira Bedina, moradora en Santiago, solicita poner al servicio de Isabel de Benavente y de Fernando Díaz, bordadores de Santiago, a su hijo Alonso Gómez de Becerra durante cinco años para que aprendiese el oficio de bordador ${ }^{33}$. En el año 1541 Fernán Díaz contrata con la Cofradía de los Clérigos del Coro de la Catedral de Santiago la realización de un paño para cubrir el ataúd que se utilizaba

\footnotetext{
30 ACS. P012/1, fols. 400r-401v. ACS. P012/1, fols. 400r-401v.

31 Archivo Histórico Universitario de Santiago de Compostela (en adelante) AHUSC. Protocolos, S-191, fols. 581r-581v. 03-04-1536.

32 AHUSC. Protocolos, S-191, fols. 491r-492v. 26-07-1536.

33 AHUSC. Protocolos-197, fols. 118r-119r. 16-03-1539.
} 
en el entierro de los cofrades de la misma ${ }^{34}$.Un año más tarde lleva a cabo un concierto con Gregorio Benavente, bordador vecino de Medina del Río Seco, para dividir las ganancias que tuvieran en sus oficios ${ }^{35}$. En 1543 Rodrigo Pérez, escribano del arriendo, traspasa la mitad de una casa, sita en la rúa compostelana del Vilar, a favor de este artista que vivía en ella ${ }^{36}$. Dos años más tarde lo encontramos siéndole entregado un poder para ser tutor y curador de los hijos de Pedro Fernández e Isabel Benavente ${ }^{37}$. Una escritura constata el arrendamiento por tres años de este bordador por sí y en nombre de María Gómez, viuda de Juan Gómez, cerero, a Juan do Campo, vecino de Santiago, de una casa sita en la corredera de Santa Clara ${ }^{38}$.

De 1550 es una carta de pago de Juan de Mondragón, cardenal de Santiago, en nombre de Juan Álvarez, prior del monasterio de Santa María de Sar, a Fernándo Díaz como fiador de Gonzalo de Outeiro, vecino de Santa María de Budiño ${ }^{39}$. Otro concierto lo lleva a cabo con Pedro Maldonado de la Carrera, canónigo de Santiago, como testamentario del testamento del bachiller Pedro López, difunto, y Vasco Calvo, en nombre de la cofradía de los clérigos del coro de Santiago, relativo a la entrega por parte del citado bordador de dos cenefas de terciopelo a cambio de veintiocho ducados más la entrega por parte de los primeros de doce ducados para comprar más terciopelo para ornamentos y la entrega de cierta plata que le fue rematada de los bienes del dicho bachiller difunto ${ }^{40}$. De nuevo se menciona en una escritura de dote otorgada por Francisco Rodríguez, escribano, vecino de Muros a este bordador por razón de su casamiento con María Rodríguez, hermana del otorgante. En dicho manuscrito se incluye la petición por parte de Agustín Perez, en nombre de María Rodríguez de un traslado de la citada escritura por el pleito que trata con los acreedores a sus bienes dotales ${ }^{41}$. Por último, del año 1570 hayamos una curiosa noticia relacionada con el mismo. Concretamente se trata de una donación hecha por María Rodríguez, por entonces viuda de Fernán Díaz, a Pedro de Bosende, hombre mancebo, rico y de buena casta con quién pretendía casarse para su remedio y sustento, de todos sus bienes muebles y raíces ${ }^{42}$.

\footnotetext{
${ }^{34}$ ACS. P008, fol. 229. 11-02-1541.

35 ACS. P022, fols. 205r-206v.

${ }^{36}$ ACS. P015, fol. 19. 09-08-1543

${ }^{37}$ ACS.P020/1, fols. 141v-142r. 04-09-1945

38 AHUSC. Protocolos, S-211, fols. 225v-226. 24-03-1548.

39 AHUSC. Protocolos, S-213, fol. 146r. 11-01-1550.

40 AHUSC. Protocolos, S-280, fol. 179. 28-02-1551.

${ }^{41}$ AHUSC. Protocolos, S-227, fols. 500-501. 20-05-1559

${ }^{42}$ ACS. P048, fols. 515r-516r. 20-05-1570.
} 
EL ARTE DEL BORDADO EN SANTIAGO DE COMPOSTELA.

\section{GONZALO DE LUACES}

De 1544 es la primera noticia, hasta ahora inédita, que hemos hallado de este broslador. Hace referencia a su formación artística. En ella aparece como criado del bordador Fernán Díaz el cual le otorga un poder para que pueda cobrar de Antonio Fernández, mercader, avecindado en la ciudad de Orense, cuarenta reales de plata ${ }^{43}$. Cristóbal de Balbuena, vecino de Rozamonde, contrata con Gonzalo de Luaces la hechura de dos dalmáticas de raso falso colorado con sus collares ${ }^{44}$. En nombre de su hermano Bernardo de Luaces traspasa a Manuel Correa, mercader de Santiago, una casa en la Rúa do Vilar que tenía en arriendo de Pedro de Luaces, mercader de Santiago ${ }^{45}$. En 1566 firma un contrato con Juan Cotón, clérigo, por el que este último se obliga a decir misas los domingos y días señalados en la capilla de San Pedro de la Catedral de Santiago a cambio de seis ducados ${ }^{46}$. Un año más tarde arrendará a Juan de Santiago, azabachero, una casa con su tienda y bodega sita en la vía Sacra durante siete años y por una renta anual de veintidós ducados y dos reales ${ }^{47}$. Con Juan Ortega, clérigo vecino de la ciudad de Santiago y rector del beneficio de Santa María de Morlán y Gregorio Pérez, vecino de la dicha parroquia llevará a cabo una concordia por la cual ha de hacer una manga de una cruz de raso colorado, con sus extremos de raso amarillo. Todo ello por un total de sesenta y nueve reales ${ }^{48}$.

De 1569 son varios contratos. El primero de ellos lo firma con los vecinos y parroquianos de la feligresía de Santa María de Figueiras con quienes se compromete a bordar una casulla, frontal, guarniciones de alba, estola y un manípulo de damasco blanco a cambio de treinta y siete ducados ${ }^{49}$. Unos meses más tarde concierta con el padre Fray Juan de Leria, prior del monasterio de San Xoán de Poio realizar para el abad del citado monasterio una casulla y otras vestiduras por el precio de cuarenta y cinco ducados ${ }^{50}$. Y el 16 de agosto de este mismo año rubrica un contrato diferente a los anteriores. Este tiene que ver con la reforma de su propia vivienda. Llega a un acuerdo con García de Celaya, cantero para que le haga en la delantera de la casa que el bordador tiene arrendada en la vía Sacra una pared de piedra con sendas puertas y otro muro en la huerta de la vivienda a cambio de 52 reales $^{51}$. El 14 de abril de 1570 se compromete con Do-

\footnotetext{
43 ACS. P017, fols. 319r-320v. 28-05-1544.

44 AHUSC. Protocolos, S-219, fols. 200r-200v. 27-07-1555.

45 AHUSC. Protocolos, S-229, fols. 94r-95r. 08-01-1564.

46 ACS. P039, fols. 484r-485r. 06-01-1566.

47 ACS P039, fols. 610r-611v. 13-07-1566.

48 ACS. P042, fols. 39r-40r. 31-03-1568.

49 ACS. P045, fols. 813r-814v. 27-02-1569.

50 ACS. P046/1, fols 882r-883r. 29-04-1569.

51 ACS. P045/1, fols. 134r-135v- 16-08-1569.
} 
mingo de Castro, escribano y vecino de la feligresía de Santa María de Vigo, a tejer para la citada iglesia dos dalmáticas de damasco blanco y otras cosas a cambio de setenta y dos ducados ${ }^{52}$. Este mismo año Gonzalo de Luaces otorga carta de pago a Fray Juan Biloria, monje benedictino del monasterio de San Juan de Poio, el cual le pagó los cuarenta ducados en que se había concertado la hechura de una casulla ${ }^{53}$. Otra carta de pago recoge el pago de dieciocho ducados a este bordador por parte de Agustín de Mondragón, cardenal de Santiago, Pedro de Mondragón, canónigo de Santiago y Juan de Mondragón, racionero de Santiago, cumplidores del ánima y testamento del difunto cardenal Juan de Mondragón, a razón de los aderezos que realizó en la capilla de Nuestra Señora de la Piedad ${ }^{54}$. De 1576 es el recuento de los bienes de este bordador. Se incluye la solicitud par parte de Isabel Pérez, viuda del citado artista, a Nuño Álvarez de Sebil, justicia y alcalde ordinario de Santiago para que se haga tasación y valoración de ciertos bienes de oro, plata y seda que quedaron del dicho difunto ${ }^{55}$.

\section{PedRo CREspo}

En 1550 está rubricado el testamento de Francisca de Cisneros, mujer de Pedro Crespo, bordador estante en Santiago ${ }^{56}$.

\section{JuAN DE PINEDA}

Este bordador, estante y residente en Santiago, concierta con Juan García, natural de Portomarían, la formación de este último en el referido oficio, viviendo en su compañía durante cuatro años, el cual le servirá durante dicho tiempo como su criado ${ }^{57}$.

\section{FERNANDO VÁZQUEZ}

Alfonso de Neira, clérigo, firma un contrato con Fernando Vázquez, para poner a Gonzalo Pérez durante seis años al servicio de este bordador de Santiago para que aprenda el oficio ${ }^{58}$. De 1587 es el testamento, recuento e inventario de este bordador de Santiago de Compostela ${ }^{59}$.

\footnotetext{
${ }^{52}$ ACS. P048, fols. 122r-123v. 04-04-1570.

${ }^{53}$ ACS. P048, fol. 379v. 30-04-1570.

${ }^{54}$ ACS. 0063/2, fol. 120v. 21-01-1575.

55 AHUSC. Protocolos, S-415, fols. 53-71. 03-01-1576.

56 AHUSC. Protocolos. S-249, fols. 217-218. 27-02-1550.

57 AHUSC. Protocolos, S-214, fol. 361. 19-05-1551.

${ }^{58}$ AHUSC. Protocolos, S-219, fols. 109r-109v. 09-09-1555.

${ }^{59}$ AHUSC. Protocolos, S-128, fols. 180-187. 1557.
} 


\section{LoPe PÉREZ DA CANA}

Se cita en una relajación hecha por este artista, bordador vecino de Santiago, a favor del labrador Alonso de Lestón y su mujer Alberta Fernández, vecinos de Muros, de la tercera parte de una huerta sita junto a la fuente de Sancti Spiritus de Muros en pago de los quince ducados que le prestara ${ }^{60}$.

\section{PIERRE BigARNY}

Pierre Bigarny, bordador vecino en la ciudad de Santiago, aparece dando un poder a favor de Pedro Huga, tratante y vecino de la ciudad de A Coruña, para que pueda cobrar de Jaques Zapatero, vecino de la citada ciudad, una ropeta de Londres $^{61}$.

\section{Miguel RodríGuez dA CANA}

Se menciona a Miguel Rodríguez da Cana en un fragmento de la venta hecho por Juan Cotón, vecino de la ciudad de Santiago, a favor del citado bordador, de una casa en lugar de Sigüeiro por veinticuatro ducados ${ }^{62}$. En 1563 vende a la Cofradía de los clérigos del coro, el derecho útil y la parte y quiñón del lugar y casal do Casal que tenía en foro de la dicha Cofradía sito en la feligresía de Santa María de Cesar ${ }^{63}$. El testamento de Miguel Rodríguez da Cana, bordador en el barrio de Santa Clara de Santiago de Compostela, se fecha en $1569^{64}$.

\section{JUAN DE ROMAY}

La primera noticia encontrada hace referencia a la dote otorgada por Sancho de Palomares, racionero de Santiago, por el casamiento entre Juan de Romay con Catalina Palomares, su pariente, entregándole a la dicha Catalina, trescientos ducados, así como una cama de ropa y cuatro cargas de trigo y cuatro de centeno ${ }^{65}$. En 1586 se lleva a cavo una venta por parte del monasterio de Santa María de Belvisa a favor de Juan de Romay y Catalina de Palomares, su mujer, de una media casa en la rúa de Vilar por precio de 38 ducados $^{66}$. Dos años más tarde encontramos una carta de pago otorgada a este artista junto a Lope Cotón, azabachero, como

\footnotetext{
60 AHUSC. Protocolos. N30, fols. 35-36. 13-04-1563.

61 ACS. P044, fols. 16r-16v. 30-10-1568.

62 ACS. P046/1, fol. 672v. 15..?

63 AHUSC. Protocolos. S-229, fols. 167r-168v. 11-12-1563.

64 AHUSC. Protocolos. S-363, fols. 384-386. 1569.

65 ACS. P049, fols. 482r-484v. 20-01-1571.

66 ACS. P096, fols. 182r-184r. 07-01-1586.
} 
mayordomos de las cofradías de San Esteban y San Sebastián respectivamente, a favor de Jácome Rodríguez de Somoza, vecino de Santiago, que les entregó dos libras de cera relativos a los blandones y cera que llevaron para las honras de la difunta María Sánchez de Somoza ${ }^{67}$. De 1590 es una carta de pago de Juan de Romay a favor de Juan de Mayo, vecino de la villa de Muros y procurador de ella, de 393 reales por razón de la hechura de una casulla y otras cosas ${ }^{68}$. Y en 1600 firma una concordia con Rodrigo Suárez del Reino, canónigo de Padro, por el cual el segundo asienta con el bordador a Miguel Suárez, su pariente, por tres años y medio para que le enseñe el mencionado oficio mientras le presta servicio ${ }^{69}$.

\section{ENRIQUe COLETE}

En 1589 se lleva a cabo un arriendo hecho por Mayor Yáñez da Cana, viuda de Pedro Douteiro, mercader, vecina de Santiago, a Enrique Colete, bordador y vecino de la misma ciudad, de una casa situada tras la carnicería de la ciudad junto al monasterio de San Paio de Antealtares, durante cuatro años y por una renta anual de ocho ducados ${ }^{70}$.

\section{Catalina de Palomares}

Esta bordadora viuda de Juan de Romay se compromete con Domingo de Castelo, vecino de Santiago de Castelo para realizarle ciertas prendas a cambio de sesenta y un ducados y dos reales y medio ${ }^{71}$.

\section{AlOnSO HERNÁNDEZ}

Aparece citado este bordador, vecino de Santiago, en un contrato de aprendizaje que firma con Dominga López, vecina de la misma ciudad, para que el primero enseñe a Diego Vélez, hijo de la dicha Dominga, el oficio de bordador durante cuatro años y por precio de cuatrocientos reales ${ }^{72}$.

\section{Miguel SuÁREZ DE RomaY}

El 23 de mayo de 1608 se fecha un contrato firmado por Alonso Douteiro, mayordomo de la parroquial de Santa Comba de Louro, con Miguel Suárez, bor-

\footnotetext{
${ }^{67}$ ACS. P101, fol. 129v. 15-02-1588.

68 ACS. P106, fols. 416r-417r. 05-09-1590.

${ }^{69}$ AHUSC. Protocolos. S-687, fol. 572. 16-03-1600.

${ }^{70}$ ACS. P103, fols. 122r-123v. 14-07-1589.

${ }^{71}$ AHUSC. Protocolos, S-687, fol. 273. 22-06-1600.

${ }^{72}$ ACS. P131, fols. 361r-362r. 22-05-1606.
} 
dador y vecino de Santiago, que ha de hacer una manga de terciopelo carmesí con sus frisas de tela de oro, cordones de seda y oro con flocaduras de lo mismo para la cofradía del Santísimo Sacramento de dicha feligresía, por una suma de cuarenta ducados. Un mes después firma un contrato con Juan García, mayordomo de Saiar para realizar unos frontales para la citada iglesia pagándole lo que dijera el licenciado Alonso López, canónigo en Santiago ${ }^{73}$. En 1612, Juan Romero, cirujano, arrienda a Miguel Suarez de Romay, una tienda que está debajo de la casa del primero que cae hacia la Quintana, durante seis años y por una renta anual de trece ducados ${ }^{74}$.

Juan Falcón, labrador, vecino de la feligresía de San Salvador de Sabradelo, patrón de la capilla de San Marcos, inclusa en la iglesia de Santa María de Caleiro de la villa de Vilanova de Arousa, contrata con el citado bordador la realización de una casulla por precio de cuarenta y un ducados ${ }^{75}$. Asimismo firma otro contrato con el anteriormente citado mismo Juan Falcón con el cual se compromete a bordar una casulla y un frontal de damasco blanco con sus cenefas de brocatel y franjones de oro, con su estola y manípulo ${ }^{76}$. En 1629 vende junto a su mujer María Ordoñez una casa, sita en la rúa de Abril Ares a Pedro Rodríguez, cordonero, y a su mujer Marquesa Cardoso, en precio de ciento cincuenta y seis duca$\operatorname{dos}^{77}$.

\section{FERNANDO ÁLVAREZ}

En 1606 se fecha el testamento de Ana Romera, su mujer ${ }^{78}$. De tres años después es un contrato firmado entre el licenciado Bermúdez de Castro, cardenal en la iglesia de Santiago, en nombre de la cofradía de los clérigos de la Mahía y Xiro y Fernando Álvarez, bordador vecino de Santiago, por el cual este último ha de hacer un terno entero de difuntos, por precio según la tasación de dos oficiales del dicho oficio ${ }^{79}$. En 1611 firma una concordia con Gregorio Viéitez y Gonzalo de Sarrapio, vecinos de la San Isidro de Montes, mayordomos que han sido de la citada parroquial, para hacer una casulla de damasco negro con cenefa de damasco carmesí y su estola y manípulo de lo mismo a cambio de lo que tase el provisor del arzobispado ${ }^{80}$. Documento similar al último es el que firma con

\footnotetext{
73 ACS. P137/1, fols. 189r-189v. 27-09-1608.

74 ACS. P146, fols. 144r-144v. 15-03-1612.

75 ACS. P148, fols. 194r-194v. 07-12-1612.

76 ACS. P150, fols. 163r-163v. 13-01-1613.

77 ACS. P163, fols. 119r-123v. 02-11-1629.

78 AHUSC. Protocolos. S-806, fols. 358-359. 1606.

79 ACS. P138, fols. 342r-343v. 20-02-1609.

80 ACS. P145, fols. 208r-209r- 19-10-1611.
} 
Domingo Buxía, labrador y vecino de Santa María de Val de Rus, como mayordomo de la fábrica de dicha parroquia, para que borde dos casullas con sus estolas y manípulos recibiendo de antemano ocho ducados ${ }^{81}$. También de 1611 es un contrato entre este bordador y el bachiller Francisco Seoane, clérigo de Santa Baia de Dumbría, por el cual el dicho artista ha de hacer una casulla por precio de seiscientos veinticinco reales a lo que hay que sumar ciento cincuenta y cuatro de una casulla que el dicho bachiller entregó con anterioridad ${ }^{82}$.

El 10 de febrero de 1612 está fechada una carta de pago otorgada por el citado bordador a favor de Juan de Espada, mayordomo de la cofradía del Santísimo Sacramento de la iglesia de San Tirso de Ambroa y otros vecinos de esta parroquial, los cuales le pagaron cincuenta y cinco ducados para saldar el pago del palio del Santísimo Sacramento y la casulla blanca con su cenefa de tela de oro que habían contratado ${ }^{83}$. Un año más tarde firma un contrato con Lope Mejuto, vecino de San Esteban de Pezobres y Juan Mouriño, vecino de Santaia de Serantes para bordar una dalmática de damasco carmesí a cambio de cincuenta y ocho ducados $^{84}$. En 1617 arrienda a Juan Suárez, clérigo rector de Santa María de Sar, del agro que está detrás de la ermita de San Blas, junto al monasterio de Sar, durante nueve años y por una renta de cuatro ferradas de trigo ${ }^{85}$.

\section{BENITO DA MATA}

Aparece en una venta de Juan Mayo y su mujer María Suárez, vecinos de San Xián dos Cabaleiros, de la propiedad del medio tercio del lugar de Outeiral a este bordador por precio de treinta ducados ${ }^{86}$.

Y con este último bordador compostelano del siglo XVII terminamos el presente estudio, en el cual creemos haber conseguido superar el objetivo planteado en un principio, que no era otro que el de profundizar en algunos aspectos, aún desconocidos, de la vida y obra de estos artistas. Asimismo abrir una puerta a futuras investigaciones que de forma seria estudien esta parcela de la historia del arte gallego, por muchos olvidada.

\footnotetext{
81 ACS. P145, fols. 246r-247r- 07-12-1611.

82 ACS. P144, fols. 314r-315r. 13-08-1611.

83 ACS. P146, fols. 419r-419v. 10-02-1612.

84 ACS. P150, fols. 185r-186r. 07-03-1613.

85 ACS. P154, fols. 231r-232. 23-09-1617.

86 AHUSC. Protocolos. S-742, fols. 401-404. 29-05-1632.
} 